\title{
Chiral amides in asymmetric synthesis
}

\author{
Léon Ghosez*, Christophe Genicot and Véronique Gouverneur \\ Laboratoire de Chimie Organique de Synthèse, Université Catholique de Louvain, place Louis \\ Pasteur 1, 1348 Louvain-la-Neuve, Belgium
}

\begin{abstract}
New strategies for the asymmetric vicinal acylation of olefins and the synthesis of enantiomerically pure amino acids are presented. Both use, as key step, a cycloaddition reaction involving a reagent easily prepared from chiral amides derived from pyrrolidines with $\mathrm{C}_{2}$ symmetry.
\end{abstract}

\section{INTRODUCTION}

Racemic compounds are mixtures of compounds which generally show different behaviour towards biological systems. It is thus expected that they will not longer be accepted for applications in the pharmaceutical and agrochemical fields. As a result, the preparation of enantiomerically pure compounds has become a major endeavour for organic chemists. Over the past five years, our laboratory has been developing new classes of carboxamide synthons which perform effectively in enantioselective transformations. In this paper we shall briefly describe some recent results using two new reagents which are readily accessible from simple carboxamides (Scheme 1).

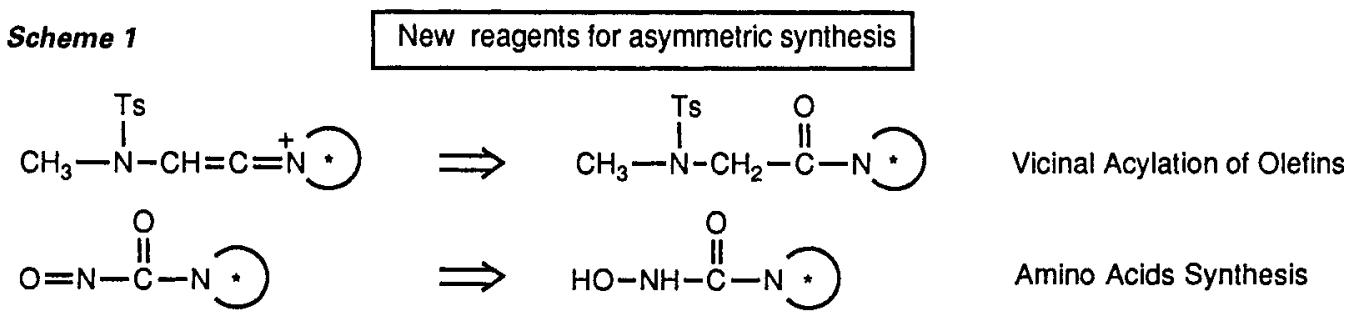

\section{VICINAL ACYLATION OF OLEFINS}

A short sequence leading to the regio- and stereoselective addition of a carboxyl and a carbonyl group to an olefinic double bond has been recently reported by our group. 1 The strategy involves the $[2+2]$ cycloaddition of an olefin to a keteniminium salt 1 derived from $\mathrm{N}$-tosyl sarcosinamide 2 , followed by a regiospecific oxidation of the hydrolysed adduct 3 (Scheme 2).

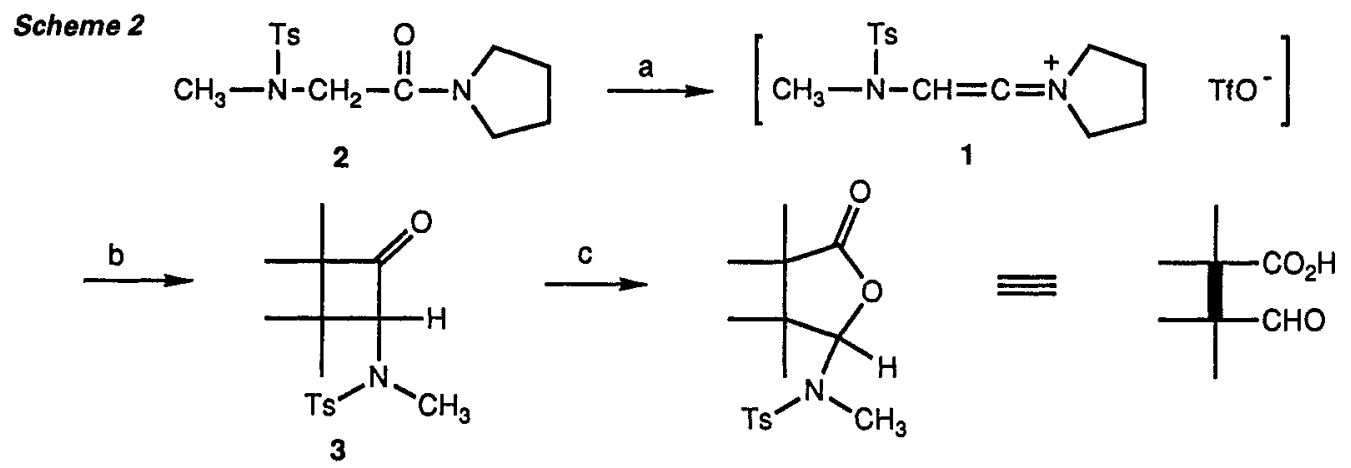

Conditions : (a) $\mathrm{Tf}_{2} \mathrm{O}$, collidine or 2,6-ditertbutyl-4-methylpyridine, 1-2-dichloroethane; (b) olefin, $20^{\circ}$ then $\mathrm{H}_{2} \mathrm{O}-\mathrm{CCl}$; (c) $\mathrm{mCPBA}, \mathrm{NaHCO}_{3}, \mathrm{CH}_{2} \mathrm{Cl}_{2}$. 
The functionalized keteniminium salt $\mathbf{1}$ is an ideal reagent for the sequence : (a) it is highly reactive and readily cycloadds even to olefins bearing no activating groups, (b) it gives crystalline easily purified products, (c) it bears a heterosubstituent at $\mathrm{C}-2$ which provides the required oxidation level and controls the regioselectivity of the oxidation step.

The sequence represents a short and practical method to attach a carboxyl and a carbonyl group to an olefinic double bond. 2 However this version only leads to racemic mixtures.

In previous studies 3 we have observed asymmetric inductions in cycloadditions of olefins with a keteniminium salt prepared from isobutyramide, itself derived from prolinol methyl ether. However we did not expect that the amide 4 derived from $\mathrm{N}$-tosyl sarcosine and prolinol methyl ether could be used successfully. Amide $\mathbf{4}$ can indeed generate two diastereoisomeric keteniminium salts $5 \mathrm{a}$ and $\mathbf{5 b}$ which would be expected to react with different facial selectivities (Scheme 3).

Scheme 3<smiles>[Y]CC(=O)N1CCCC1</smiles>

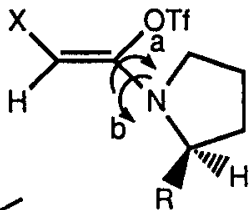

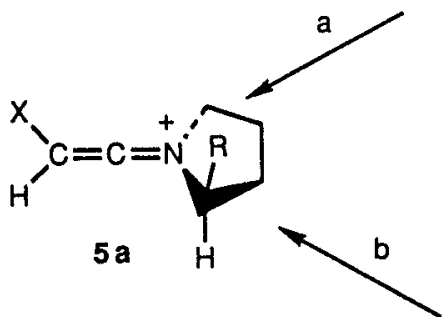<smiles>[Y4]C(=O)N1CCC[C@H]1[2H]</smiles>

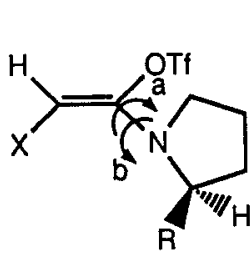<smiles>[PbH2]C1CCCCC1</smiles>

$X=$ NMeTs

$\mathrm{R}=\mathrm{CH}_{2} \mathrm{OMe}$

We were thus not surprised to observe poor enantiomeric excesses in the reaction of 5 with terminal olefins e.g. styrene (Scheme 4). However keteniminium salts 5 and cyclic olefins reacted with high facial selectivities. These intriguing results suggest the preferred formation of one of the diastereoisomeric salts $\mathbf{5 a}$ or $\mathbf{5 b}$. This interesting finding certainly deserves further studies.

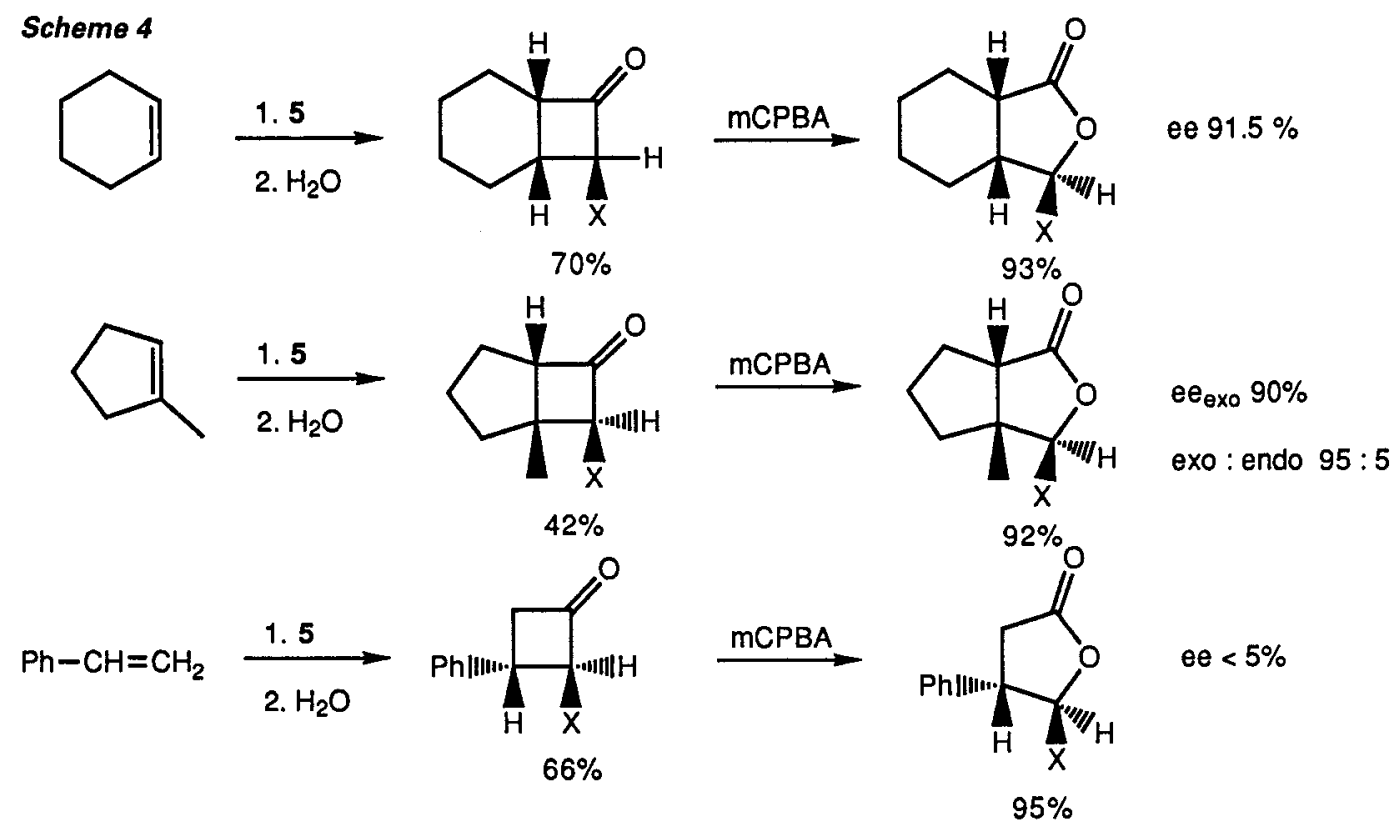


The formation of two diastereoisomeric keteniminium salts will obviously be suppressed by using $\mathrm{N}$-tosyl sarcosinamide derived from 2,5-disubstituted pyrrolidines possessing $\mathrm{C}_{2}$ symmetry (Scheme 5). 4

\section{Scheme 5}<smiles>CO[C@H]1CN(C(=O)CN([13CH3])[13CH3])C[C@H]1OC</smiles>

6<smiles>COC[C@H]1CC[C@H](CO)N1C(=O)CN(C)[As]</smiles><smiles>C[C@@H]1CC[C@@H](C)N1C(=O)CN([AsH3])[AsH3-]</smiles>

Amide 6 gave a good yield of cyclobutanone but poor enantiomeric excesses. Substituents of the pyrrolidine ring are clearly too far away from the reacting centres. In contrast with the amide 5 derived from prolinol methyl ether, the corresponding disubstituted amide 7 with $\mathrm{C}_{2}$ symmetry gave no cyclobutanone. This is an illustration of the pitfall which $C_{2}$ symmetry can present, i.e. a substantial decrease of reactivity resulting from the shielding of both diastereotopic faces of the molecule. Shortening the substituents' chain (compound 8) provided us with a satisfactory compromise. When the sequence was applied to cyclic olefins, the ring fused cyclobutanones 9 and $\gamma$-lactones 10 were obtained in good yields and enantiomeric excesses greater than $90 \%$. One recrystallization gave the enantiomerically pure lactones.

\section{Scheme 6}<smiles>C[C@@H]1CC[C@@H](C)N1C(=O)CN(C)C(F)(F)F</smiles>

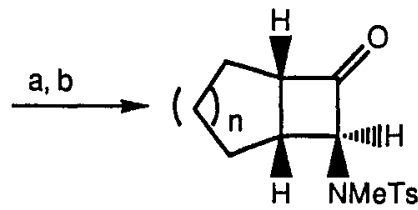

$9 n=175 \%$

$n=2 \quad 81 \%$

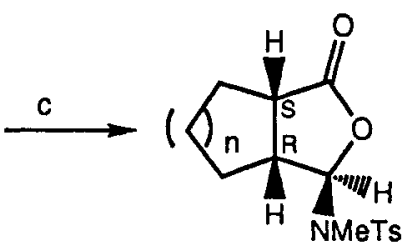

$10 n=196 \%$ ee $91 \%$

$n=2 \quad 93 \%$ ee $93 \%$

Conditions $a, b, c$ as in Scheme 2

Both cis- and trans- butene yielded the trans- 3, 4-dimethylcyclobutanone (trans : cis, $19: 1$ ) as a result of a fast epimerization of the intermediate cyclobutaniminium salt. The oxidation of the pure trans isomer derived from the cis isomer yielded a lactone 11 of high enantiomeric purity (Scheme 7). The lactone originating from the adduct derived from trans- butene had the opposite configuration and a smaller enantiomeric purity.

\section{Scheme 7}

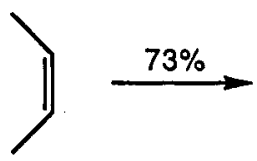

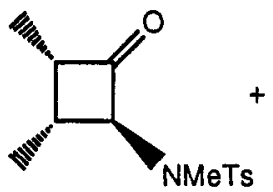

1

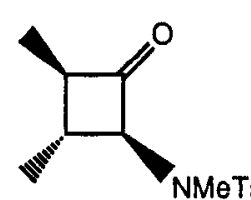

19

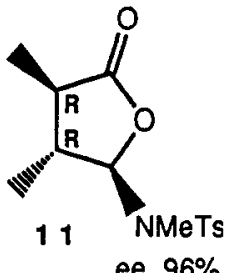

ee $96 \%$

The sequence was applied successfully to other di- and tri-substituted olefins but a limitation was found with terminal olefins which yielded adduct of low enantiomeric purities $(\sim 30$ to $50 \%$ ee).

All the results can be readily explained by the stepwise mechanism proposed earlier $3 \mathrm{~b}$ (Scheme 8). Approaches A and B from the $\alpha$ face suffer from less steric repulsion than other approaches from either face. However, this model does not easily differentiate paths $A$ and $B$. On the basis of the observed absolute configuration, path B seems to be the favoured one. 


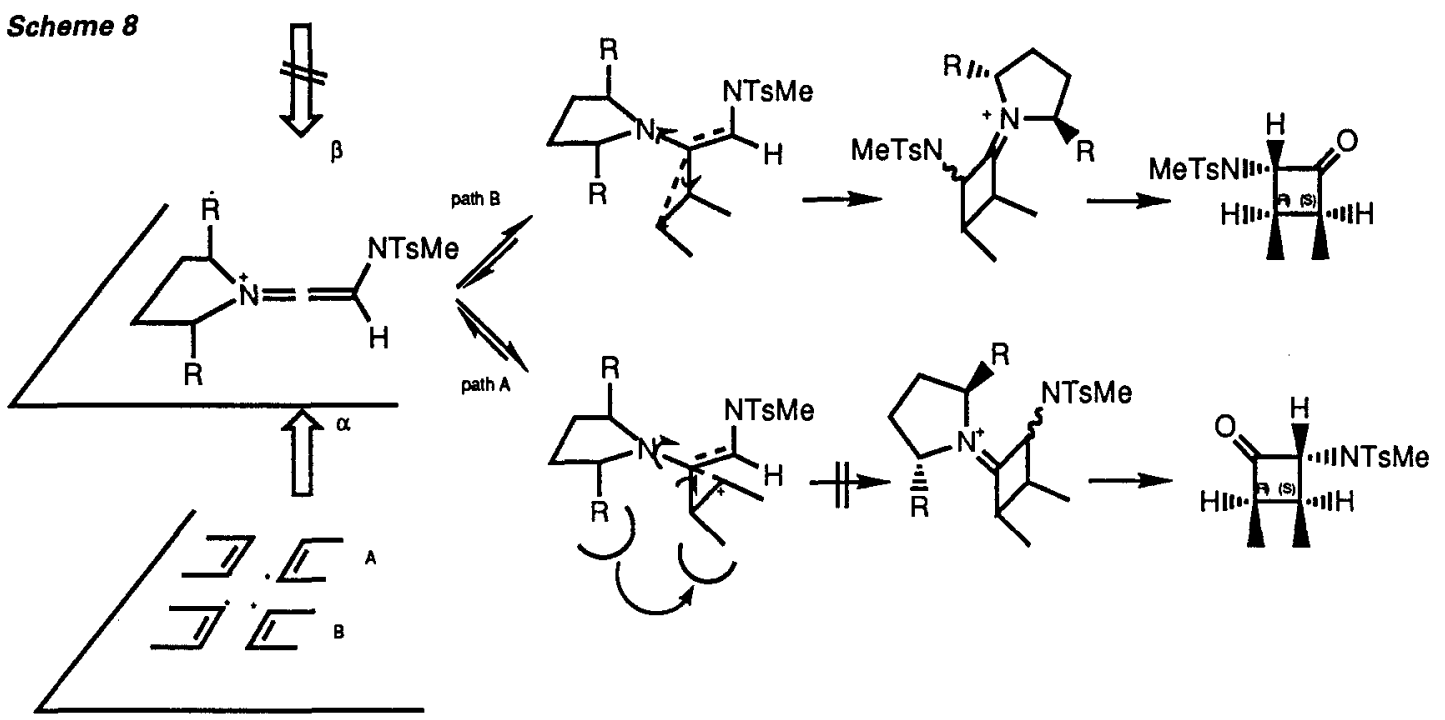

Since we have shown that the NTsMe group could be readily exchanged for $\mathrm{OH}$ or any alkoxy substituent, the results presented here provide a fairly general method for the asymmetric acylation of olefins.

\section{ASYMMETRIC AMINATION OF CARBOCYCLIC ACIDS VIA A DIELS-ALDER STRATEGY: A NEW ROUTE TO ENANTIOMERICALLY PURE AMINO ACIDS}

Only a few asymmetric syntheses of $\alpha$-amino acids by electrophilic amination of carboxylic acid derivatives have been described. Most of the methods reported to date are based on the reaction of chiral enolates with azodicarboxylate esters, 1-chloro-1-nitroso-cyclohexane, or azide reagents as aminating reagents. 5 We have worked out an alternative approach which uses the Diels-Alder reaction of 2-azadienes with chiral acylnitroso compounds for the stereocontrolled formation of the new $\mathrm{C}-\mathrm{N}$ bond. This strategy is outlined in Scheme 9.

\section{Scheme 9}

$$
\mathrm{R}-\mathrm{CH}_{2}-\mathrm{CO}_{2} \mathrm{H}
$$<smiles>[X]C=NC(=C[R])O[AsH2]</smiles><smiles>O=C(NC1CCCC1)C(=O)N1CCCCC1</smiles>

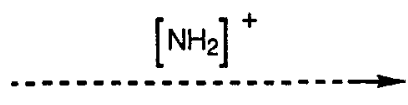<smiles>[X]C1NC(=O)[C@H](P)N(C(=O)n2cccc2)O1</smiles><smiles>[R]C([NH3+])([NH3+])[C@@H](CC)C(=O)O</smiles><smiles>CCCCCCCCO</smiles><smiles>[R][C@@H](NC(=O)N1CCCC1)C(N)=O</smiles>

Acid chlorides can be readily and stereoselectively converted 6 into the corresponding E,Z 2 -azadienes 12 when $X$ is an isopropoxyl, aryl, or non-enolizable alkyl groups (Scheme 10).

Scheme 10

$$
\begin{aligned}
& \mathrm{R}-\mathrm{CH}_{2}-\mathrm{COCl}+\mathrm{X}-\mathrm{CH}=\mathrm{N}-\mathrm{SiMe}_{2} \mathrm{R}^{1} \\
& \mathrm{X}=\mathrm{iPropO}, \mathrm{Ph}, \mathrm{tBu}, \mathrm{R}^{1}=\mathrm{Me}, \mathrm{tBu} \\
& \mathrm{R}=\mathrm{H}, \mathrm{Me}, \mathrm{CH}_{2} \mathrm{Ph}, \mathrm{Ph}, \mathrm{CH}=\mathrm{CH}_{2}, \mathrm{CO}_{2} \mathrm{Me}, \mathrm{F}, \mathrm{Cl}
\end{aligned}
$$<smiles>[X]C=NC(=C[R])O[R16]</smiles>

18 examples

In most cases, only one stereoisomer was observed. 2-Azadienes were easily purified by distillation and were kept unchanged for several weeks in the refrigerator. However, when $X=$ isopropoxyl, it was preferable to use a bulkier silyl group $\left(R^{\prime}=t^{\prime}\right.$-butyl) to avoid decomposition during distillation. 
We found that the readily available chiral $\alpha$-chloro nitroso compounds described 8 by the groups of Kresze and Vasella could not be added to the highly nucleophilic 2-azadienes which are decomposed under the reaction conditions.

The use of the more reactive acyl nitroso compounds raises the problem of several reacting conformations. Thus moderate facial selectivities were observed 8 for the reactions of cyclic dienes such as cyclopentadiene with nitroso compounds 13,14 and 15 (Scheme 11). Locking a specific conformer by chelation would be rather difficult here because of the high instability of these acylnitroso compounds which must be generated in situ. Dienophile $13\left(\mathrm{R}^{\prime}=\mathrm{H}\right)$ which possesses a free hydroxyl group allowing for intramolecular hydrogen bonding, gave only slightly better facial selectivities.

\section{Scheme 11}

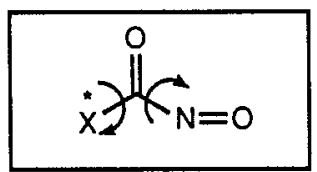<smiles>[2H][C@@H](O)C(=O)N=O</smiles>

$13 \mathrm{R}=\mathrm{Ph}, \mathrm{CC}_{6} \mathrm{H}_{11}$ $\mathrm{R}^{\prime}=\mathrm{H}, \mathrm{Me}$<smiles>CCCC(CC)C(CC)OC(=O)N=O</smiles>

14<smiles>CC12CCC(N(C(=O)N=O)C1=O)C2(C)C</smiles><smiles>COC[C@@H]1CCCN1C(=O)N=O</smiles>

15<smiles>COC[C@H]1CC[C@@](C)(COC)N1C(=O)N=O</smiles>

17

On the other hand, nitroso compound 16 derived from D-bornane-10,2-sultam reacted with cyclopentadiene or cyclohexadiene with total facial selectivity (Scheme 12).9
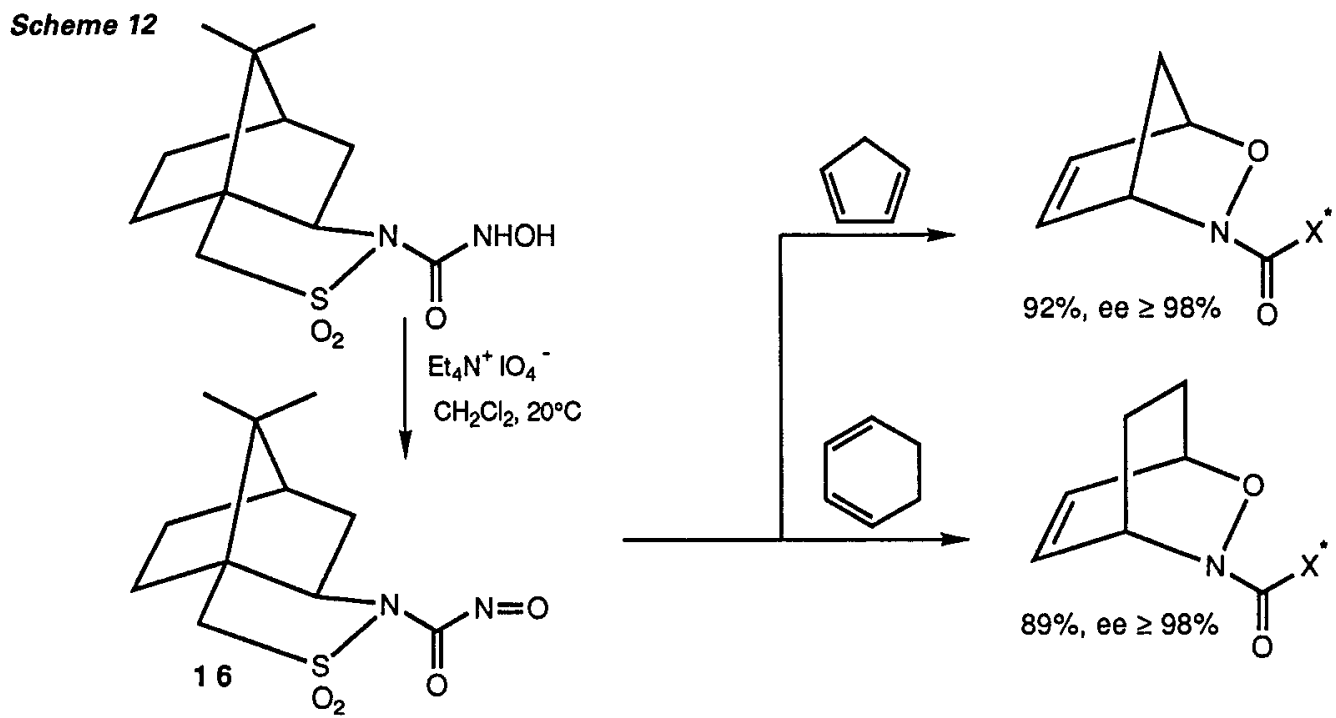

These results suggested that dienophile 16 reacts through one preferred conformation. Unfortunately the nitroso compound 16 reacted poorly with 2 -azadienes and was therefore useless for our amino acid synthesis. 
The conformational pitfall was avoided by the use of a chiral nitroso dienophile 17 with $\mathrm{C}_{2}$ symmetry (Scheme 13). Nitroso compound 17 reacted with several cyclic dienes with high facial selectivities. 10

Scheme 13<smiles>COC[C@@H]1CC[C@@H](COC)N1C(=O)NO</smiles><smiles>CC[N+](C)=O</smiles><smiles>CC1CC2CCC(C2)C1C</smiles><smiles>COC[C@@H]1CC[C@H](COC)N1C(=O)N1OC2C=CC1CC2</smiles>

$88 \%$, de $>98 \%$

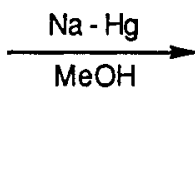<smiles>COC[C@@H]1CC[C@H](COC)N1C(=O)N[C@H]1C=C[C@@H](O)CC1</smiles>

Cycloadditions of 17 with 2-azadienes were not as successful : with the more reactive 2azadienes (Scheme $9, \mathrm{X}=\mathrm{i}$ PropO, $\mathrm{R}=\mathrm{CH}_{3}$ ) at $-20^{\circ} \mathrm{C}$, good yields of cycloadduct were obtained but the diastereoselectivity was moderate (de : $59 \%)$. With the less reactive 2 -azadiene $\left(X=P h, R=\mathrm{CH}_{3}\right)$, the facial selectivity was high $(>98 \%$ ) but chemical yields were low $(31 \%)$. The solution was clearly to work at lower temperatures with the more reactive azadiene series. However, the classical method of formation of nitroso compounds by oxidation of the corresponding hydroxamic acids with tetraethyl ammonium periodate was much too slow below $-20^{\circ} \mathrm{C}$ and degradation of the 2-azadiene occurred in this aggressive medium.

We have developed a new and efficient method for the in situ generation of acyl nitroso compounds (Scheme 14).

Scheme 14<smiles>COC[C@@H]1CC[C@H](COC)N1C(=O)NO</smiles>

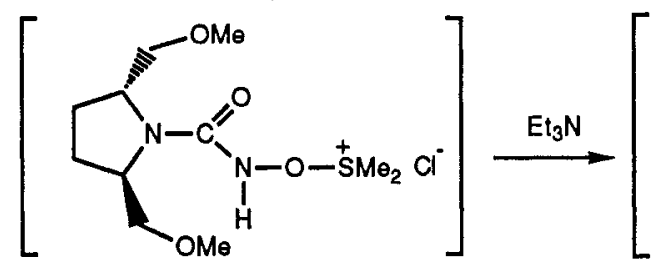<smiles>COC[C@@H]1CC[C@@H](COC)N1C(=O)N=O</smiles>

17

The hydroxamic acid was treated with the sulfonium reagent developed by Coreyll to give intermediate 18 which upon treatment with triethylamine yielded the desired nitroso compound 17. It is worth mentioning that we did not find products which could have originated from a carbamoyl nitrene produced by $\alpha$-elimination. (Scheme 15).

Armed with this new method, we proceeded with our efforts towards the desired amino acids 
The cycloadditions were regiospecific and proceeded with high diastereoselectivities. 12 Enantiomerically pure 19 were obtained after flash chromatography and one recrystallization. The reductive cleavage of the $\mathrm{N}-\mathrm{O}$ bond could be effected with reagents such as zinc in acetic acid, sodium amalgam or molybdenum hexacarbonyl in a refluxing mixture of water and acetonitrile. The reduced product 20 was hydrolysed to the free enantiomerically pure amino acid.

Scheme 15

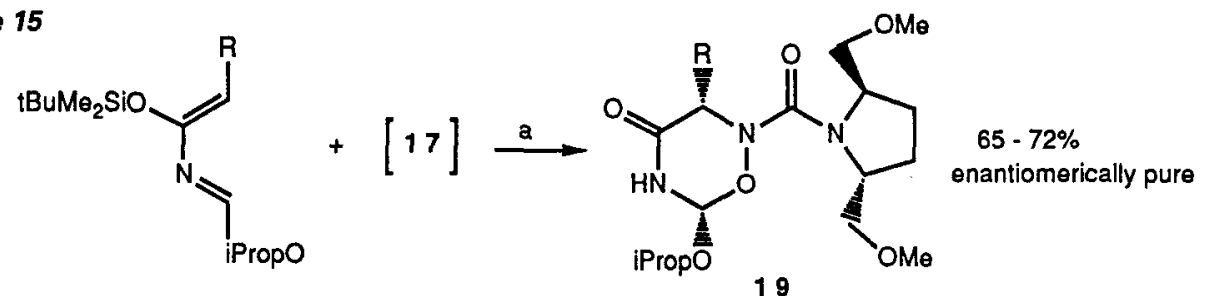

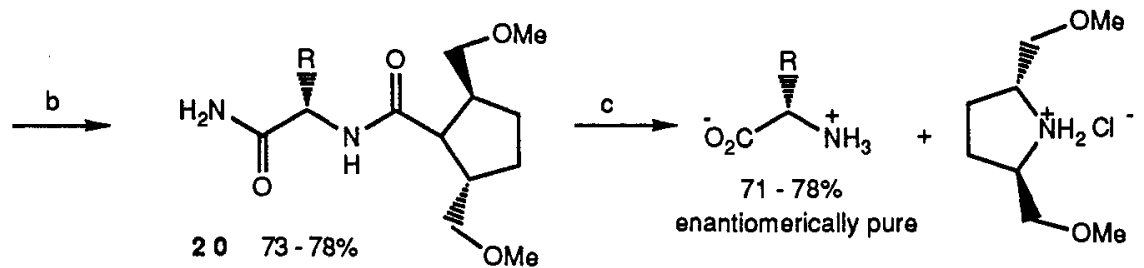

Conditions : (a) $-65^{\circ} \mathrm{C} \rightarrow-78^{\circ} \mathrm{C}$, de crude $90-94 \%$; (b) $\mathrm{Mo}\left(\mathrm{CO}_{6}\right.$ in refluxing $\mathrm{H}_{2} \mathrm{O}$ - acetonitrile; (c) $6 \mathrm{~N} \mathrm{HCl}, \Delta$

Calculations by $\mathrm{Dr}$ G. Dive predict a more stable syn conformation for the carbamoyl nitroso compound. This probably results from repulsive interactions between the oxygen atom of the $N=0$ group and the substituent of the pyrrolidine ring. The facial selectivity is consistent with transition state model A resulting from an endo approach from the less hindered side of the dienophile (Scheme 16). Both transition states B (endo) or C (exo) imply interactions with one of the substituents of the pyrrolidine ring.
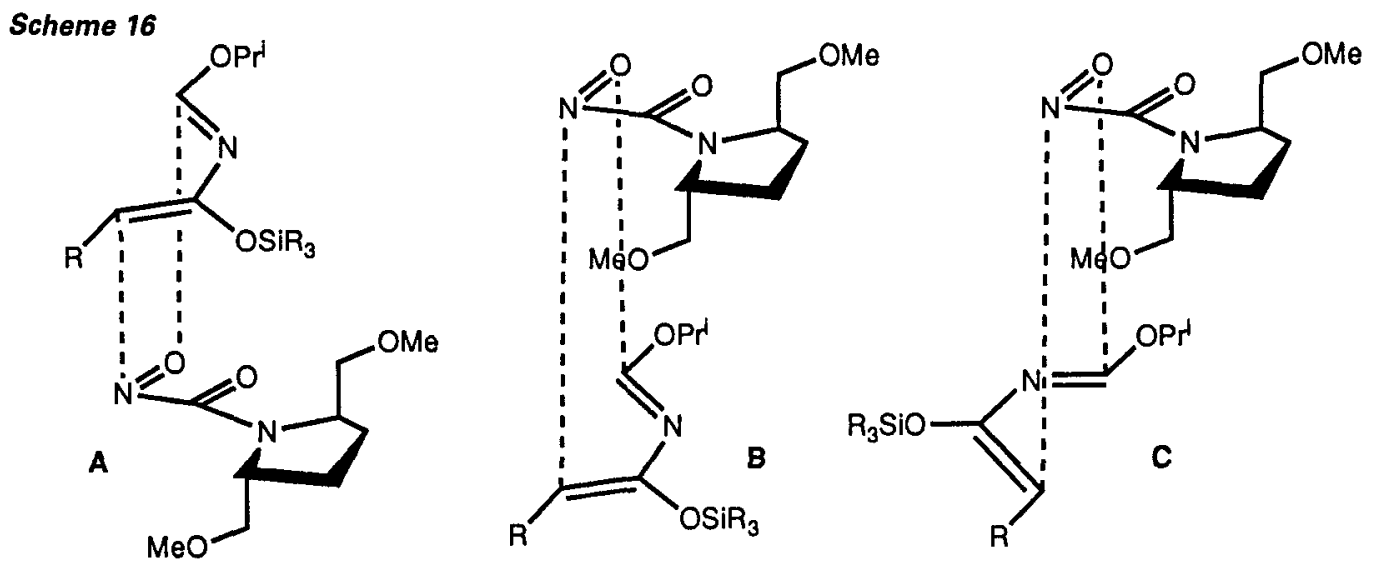

In summary this new method of amination via a Diels-Alder strategy provides a new and predictable synthetic route to enantiomerically pure $\alpha$-amino acids. The scope of the method has still to be examined as well as the application of the method to the synthesis of enantiomerically pure $\mathrm{N}$ hydroxy amino acids. An interesting fall-out of these studies is the discovery of a mild and practical method to prepare acyl nitroso compounds in situ.

\section{Acknowledgements}

We thank the following organisations for generous financial support : Ministère de l'Education et de la Recherche Scientifique de la Communauté Française de Belgique (Action Concerté 86/91-84), the Institut pour l'Encouragement de la Recherche Scientifique dans l'Industrie et l'Agriculture, the Fonds National de la Recherche Scientifique and the University of Louvain. 


\section{REFERENCES}

1. C. Genicot, B. Gobeaux and L. Ghosez, Tetrahedron Letters $\underline{32}, 3827$ (1991).

2. Vicinal dicarboxylation of olefins : (a) J.K. Stille, R. Divakaruni, J. Org. Chem. 44, 3474 (1979); (b) A.E. Greene, J.P. Deprés and F. Celho, J. Org. Chem. 50, 1972 (1985).

3. (a) C. Houge, A.M. Frisque-Hesbain, A. Mockel, L. Ghosez, J.P. Declercq, G. Germain, M. Van Meerssche, I. Am. Chem. Soc. 104, 2920 (1982)); (b) H. Saimoto, C. Houge, A.M. Frisque-Hesbain, A. Mockel and L. Ghosez, Tetrahedron Lett. 24, 2251 (1983).

4. C. Genicot and L. Ghosez, Tetrahedron Letters, submitted for publication, (1992).

5. C. Gennari, L. Colombo and G. Bertolini, J. Am. Chem. Soc. 108, 6394 (1986); D.A. Evans, T.C. Britton, R.L. Dorow and J.F. Dellaria, J. Am. Chem. Soc. 108, 6395 (1986); L.A. Trimble and J.C. Vederas, J. Am. Chem. Soc. 108,6397 (1986); W. Oppolzer and R. Moretti, Helv. Chim. Acta 69, 1923 (1986); Tetrahedron 44, 5552 (1988); G. Guanti, L. Banfi and E. Narisano, Tetrahedron 44, 5553 (1988); Tetrahedron Lett. 30, 5507 (1989); J.P. Genet, S. Juge and S. Mallart, Tetrahedron Lett. 29, 6765 (1988); D.A. Evans, J.C. Britton, J. Am. Chem. Soc. 109, 6881 (1987); M.A. Loreto, L. Pellacani, P.A. Tardella, Tetrahedron Lett. 30,2975 (1989); W. Oppolzer and O. Tamura, Tetrahedron Lett. 31, 991 (1990).

6. Ph. Bayard, F. Sainte, R. Beaudegnies and L. Ghosez, Tetrahedron Lett. 29, 3799 (1988).

7. M. Sabrini, G. Kresze, H. Braun, Tetrahedron Lett. 25, 5377 (1984); H. Felber, G. Kresze, H. Braun, A. Vasella, Tetrahedron Lett. 25, 5381 (1984); H. Braun, R. Charles, G. Kresze, M; Sabrini, J. Winkler, Liebigs Ann. 1129 (1987); G. Kresze, A. Vasella, H. Felber, A. Ritter, B. Ascheri, Rec. Trav. Chim. Pays-Bas 105, 295 (1986); H. Braun, H. Felber, G. Kresze, A. Ritter, F.P. Schmidtehen, A. Schneider, Tetrahedron 47, 403 (1991).

8. A. Defoin, H. Fritz, C. Schmidlin and J. Streith, Helv. Chim. Acta 70, 554 (1987); G.W. Kirby and M. Nazeer, Tetrahedron Lett. 29, 6173 (1988); A. Miller, T.C. Paterson, G. Procter, Synlett 32 (1989); V. Gouverneur and L. Ghosez, unpublished results.

9. V. Gouverneur, G. Dive and L. Ghosez, Tetrahedron Asym. 2, 1173 (1991).

10. V. Gouverneur and L. Ghosez, Tetrahedron Asym. 1, 363 (1990).

11. E. G. Corey, C.U. Kim, P.F. Misco, Org. Synth. Coll. Vol. VI, 220 (1988).

12. V. Gouverneur and L. Ghosez, Tetrahedron Lett. 32, 5349 (1991). 